\title{
THE IN VITRO METABOLISM OF ESTROGENS BY THE LIVER STUDIED BY MEANS OF A COLORIMETRIC METHOD ${ }^{1,2}$
}

\author{
By SEYMOUR LIEBERMAN, ${ }^{3}$ HENRY J. TAGNON, ANd PHYLLIS SCHULMAN \\ (From the Sloan-Kettering Institute for Cancer Research and Memorial Hospital, \\ New York, N. Y.)
}

(Submitted for publication November 5, 1951; accepted January 21, 1952)

Since the work of Zondek (1) the in vitro action of liver slices and liver pulp on natural estrogens is usually called inactivation because the transformation undergone by these compounds results in loss of estrogenic activity as measured by bioassay methods (2). Using these methods, Heller and Heller ( 3 ) demonstrated that liver slices could inactivate estrone. and estradiol in vitro and this work was confirmed by Singher and associates (4). Twombly and Taylor (5) showed that human liver inactivates $17-\beta$ estradiol less than does rat liver. It is generally accepted that liver mince is not as effective as slices in inactivating estradiol but De Meio, Rakoff, Cantarow and Paschkis (6), and Coppedge, Segaloff, Sarett and Altschul $(7,8)$ have shown that nicotinamide or diphosphorpyridine nucleotide enhance the activity of liver mince.

Thus the demonstration that the liver possesses the ability to inactivate estrogens has been based on bioassay methods. Until now colorimetric methods for estrogens have not been found satisfactory for the measurement of small amounts of estrogens in the presence of tissue (9) and therefore have not been suitable for the study of the metabolism. In this paper we are reporting a procedure which permits the simple colorimetric estimation of microgram amounts of estrogens, recovered after in vitro metabolic experiments with tissues. One of the advantages of this procedure is that it facilitates the study of the quantitative aspects of the reaction. This paper also presents the results obtained by this colorimetric technique in a study of the metabolic action of rat liver on 17- $\beta$ estradiol, estrone and estriol. A subsequent

1 Presented in part at the annual meeting of the American Society for Clinical Investigation, April 30, 1951, Atlantic City, N. J.

2 This work was supported in part by a grant from the National Cancer Institute of the U. S. Public Health Service.

3 Present address : Columbia University, College of Physicians and Surgeons, New York, N. Y. paper will present the results obtained with human liver and will discuss their pertinence to the problem of hyperestrinism in humans.

\section{METHODS}

1) Colorimetric method: The procedure used in this work is based on the measurement of the yellow color produced when the phenolic estrogens are coupled with tetrazotized dianisidine. This reaction was first proposed by Talbot and associates (10) and subsequently modified by Bender and Wilson (11) for the assay of estrogens in the urine. The pure estrogens, ${ }^{4} 17-\beta$ estradiol, estrone or estriol, were dissolved in $0.3 \mathrm{cc}$. of $95 \%$ redistilled ethyl alcohol. One tenth cc. of cold tetrazotized dianisidine solution was added, followed immediately by $0.75 \mathrm{cc}$. of cold $2 \%$ sodium carbonate solution. After mixing by swirling, $8 \mathrm{cc}$. of $20 \%$ sodium chloride and 20 cc. of toluene were added to the mixture. All these operations were carried out in an ice bath. ${ }^{5}$ The colored material was extracted into toluene by shaking for 10 minutes in a shaking machine. After centrifuging for two minutes at 2,500 r.p.m., the toluene layer was pipetted off and read in a Beckman quartz spectrophotometer (Model DU) at $425 \mathrm{~m} \mu$ in a $1 \mathrm{~cm}$. cell against the blank. The blank was treated as the experimental sample except that no estrogen was present.

Quantitative measurements of $17-\beta$ estradiol, estrone and estriol were obtained by this procedure between 10 and 150 micrograms, as indicated on Figure 1. The relation between optical densities and concentrations followed Beer's law between these two values. The slope of the curve was found to be similar for estrone and estradiol but different for estriol (Figure 1).

The absorption spectrum of the colored compound showed a plateau-like peak between $400 \mathrm{~m} \mu$ and $450 \mathrm{~m} \mu$ with the maximum at $425 \mathrm{~m} \mu$ approximately (Figure 2).

${ }^{4}$ Kindly supplied by Drs. E. Schwenk and E. B. Hirshbirg, Schering Corporation, Bloomfield, New Jersey.

5 The tetrazotized dianisidine solution was prepared as follows: $25 \mathrm{mg}$. of dianisidine dihydrochloride (recrystallized from ethanol) were dissolved in $3 \mathrm{cc}$. of water. Three tenths cc. of concentrated hydrochloric acid, followed by $0.6 \mathrm{cc}$. of freshly prepared $5 \%$ sodium nitrite solution were added. After thorough mixing and a five minute waiting period, $0.66 \mathrm{cc}$. of a $5 \%$ urea solution was added. The solution was prepared in an ice bath, and made freshly for each experiment. 


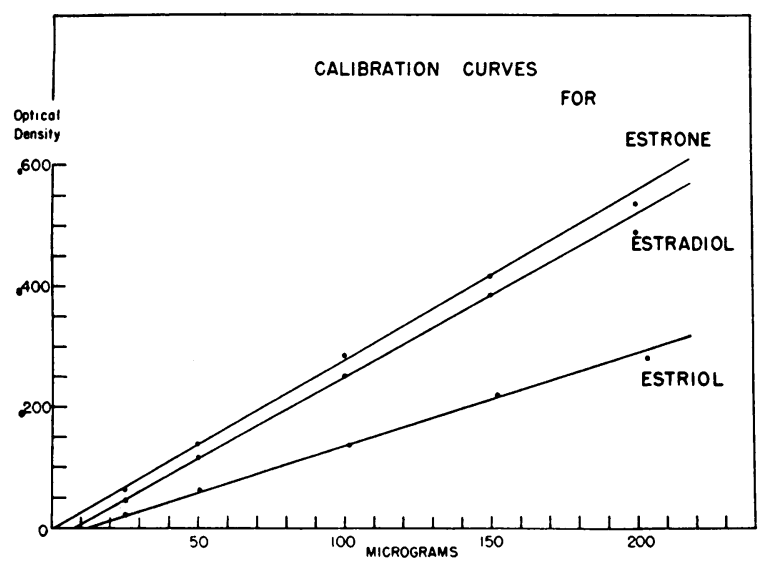

Fig. 1. Calibration Curves for Estrogens Treated with Tetrazotized Dianisidine

2) Incubation experiments: Normal albino rats, kept on a diet of purina laboratory chow, supplemented with rolled oats and flower seeds, were killed by a blow on the head, the liver obtained and sliced immediately. Three hundred $\mathrm{mg}$. of liver slices (approximately $0.5 \mathrm{mg}$. thick) were incubated with continuous shaking in an open vessel with 100 micrograms of estradiol, estrone or estriol dissolved in $0.2 \mathrm{cc}$. of $95 \%$ redistilled ethanol. Incubation was carried out in $6 \mathrm{cc}$. of Krebs solution, $\mathrm{pH} 7.4$ at $37.5^{\circ} \mathrm{C}$. As a control, $300 \mathrm{mg}$. of the same liver were boiled for 30 minutes and similarly incubated with the

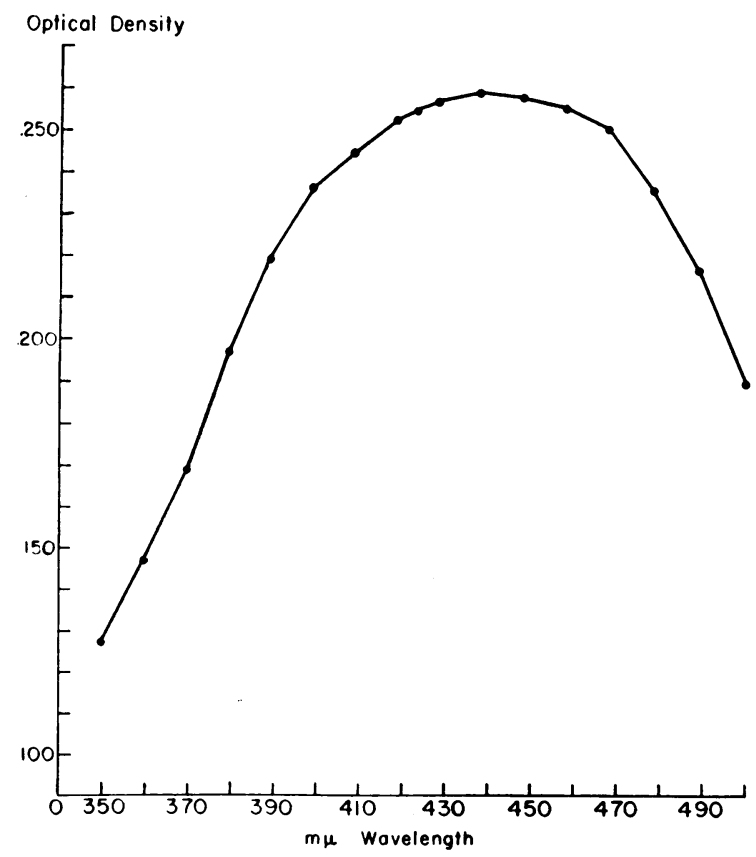

Fig. 2. Absorption Spectrum of the Colored Compound Obtained by Treatment of $17-\beta$ Estradiol, Estrone or Estriol, by Tetrazotized Dianisidine same amount of estrogen. As a blank, $300 \mathrm{mg}$. of fresh liver slices were also incubated without the addition of estrogen. At the end of the period of incubation the reaction was stopped by immersing the flasks in a boiling water bath for 30 minutes.

Thereafter, each sample was submitted to alkaline hydrolysis by adding enough solid barium hydroxide (3.8 gms. of $\mathrm{Ba}[\mathrm{OH}]_{2} \cdot 8 \mathrm{H}_{2} \mathrm{O}$ ) to make a $4 \mathrm{~N}$ solution and boiling in an oil bath for 17 hours. At the end of the period of hydrolysis the samples were allowed to cool and were brought to approximately $\mathrm{pH} 2 \mathrm{by}$ the addition of $7 \mathrm{cc} .4 \mathrm{~N}$ hydrochloric acid. The acid solution was then continuously extracted for 17 hours with redistilled benzene (approximately $60 \mathrm{cc}$.). The residue left after the evaporation of the benzene was dissolved in $0.3 \mathrm{cc}$ of 95\% redistilled ethanol and assayed colorimetrically by the method described above. The value of the control was subtracted from the value of the experimental sample.

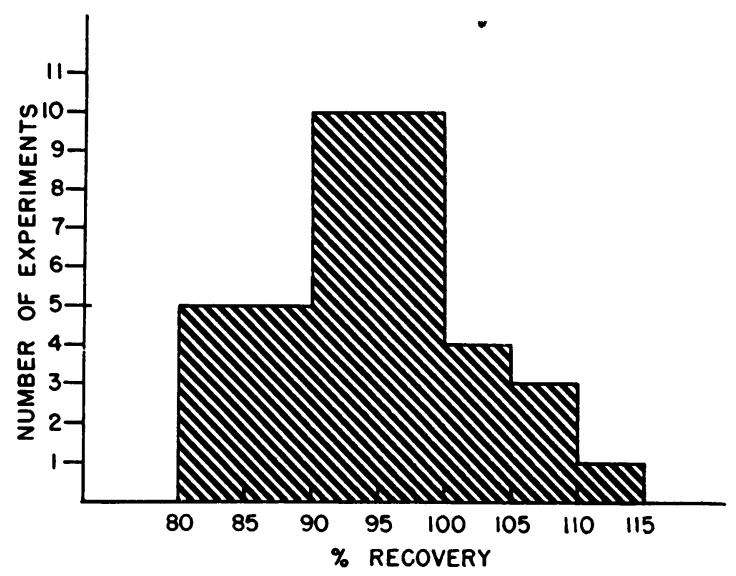

Fig. 3. Recovery Experiments with $17-\beta$ Estradiol

3) Recovery cxperiments: One hundred micrograms of $17-\beta$ estradiol were incubated for three hours with boiled rat liver slices. Recoveries ranged from $80 \%$ to $114 \%$ in 38 experiments with 20 experiments showing recoveries between 90 and $99 \%$ (Figure 3). The mean recovery value of these 38 experiments was $94 \%$ and the mean deviation or sigma value was $7 \%$. In five experiments with estrone and six experiments with estriol the average recovery was $81 \%$ and $73 \%$, respectively, with an average deviation from mean of $4 \%$ and $9 \%$ respectively (Table I).

TABLE I

Recovery of 100 micrograms of estrogen incubated with boiled rat liver

\begin{tabular}{l|c|c|c}
\hline \hline \multicolumn{1}{c|}{ Estrogen } & No. of exps. & $\begin{array}{c}\text { Mean } \\
\text { recovery } \\
\text { (micrograms) }\end{array}$ & $\begin{array}{c}\text { Average dev. } \\
\text { trom mean } \\
\text { (micrograms) }\end{array}$ \\
\hline $\begin{array}{l}\beta \text { Estradiol } \\
\text { Estrone }\end{array}$ & 38 & 94 & 7 \\
Estriol & 5 & 81 & 4 \\
& 6 & 73 & 9
\end{tabular}


The use of barium hydroxide hydrolysis improved the recoveries. This was shown by a series of experiments designed to determine the effect, on the recovery of estrogens, of barium hydroxide hydrolysis of the liver tissue prior to extraction. Boiled rat liver slices were incubated with 100 micrograms of estradiol for 45 minutes at $37.5^{\circ} \mathrm{C}$. in $6 \mathrm{cc}$. of Krebs solution. Thereafter, paired samples were extracted with and without prior hydrolysis. In 16 such experiments the average recovery of barium hydroxide hydrolyzed samples was 94 micrograms with a sigma value of $10 \%$, and that of non-hydrolyzed samples was 71 micrograms with a sigma value of $17 \%$.

Good recoveries were obtained with a 17 hour hydrolysis. Hydrolysis by means of sodium hydroxide did not yield as satisfactory results as those with barium hydroxide. As shown by Warner (12) barium hydroxide effects a more complete hydrolysis of proteins than sodium hydroxide, and this could explain the better recoveries. Recoveries were not improved by treatment of the material with a number of reagents used in an attempt to dissociate a hypothetical adsorption complex between liver tissue and estrogen. Specifically, the following reagents were ineffective: barium nitrate, urea and ammonium sulfate.

Hydrolysis with barium hydroxide for less than five hours gave incomplete recoveries, but when carried out overnight (approximately 17 hours) satisfactory results were obtained: Control experiments showed that such hydrolysis did not result in any destruction of the estrogens.

4) Extraction with benzcne: Although continuous benzene extraction of a solution of pure $17-\beta$ estradiol in $6 \mathrm{cc}$. of Krebs solution resulted in complete extraction in a period of $1 \frac{1}{2}$ hours, it was found that the length of time necessary to extract the estrogen in the presence of liver hydrolysate had to be increased to 17 hours in order to be optimally effective.

5) Color reaction: It was found necessary to carry out the color reaction on the benzene extract immediately, because the dried benzene extract could not be kept at room or even at refrigerator temperature for 24 hours without considerable loss of color-producing material. The nature of the reaction leading to this loss in the dried extract has not been investigated. However, it was found that the extracts could be kept for at least three days in the deep freeze $\left(-15^{\circ} \mathrm{C}\right.$.) without loss of color-producing material.

\section{RESULTS}

The results of metabolic experiments were obtained by subtracting the amount of estrogen recovered at the end of the incubation period from the mean value of estrogen obtained in the recovery experiments (Methods: section 3).

1) Metabolism of 17- $\beta$ estradiol, estrone or estriol by liver slices as measured colorimetrically: When 100 micrograms of estradiol were incubated at $37^{\circ} \mathrm{C}$. with $300 \mathrm{mg}$. of fresh liver slices for three
TABLE II

Amount of estrogens metabolized by fresh rat liver (pH, 7.4; Temp., 37.5 ${ }^{\circ} \mathrm{C}$; Amount of liver, $300 \mathrm{mg}$. )

\begin{tabular}{l|c|c|c}
\hline \hline Estrogen & No. of exps. & $\begin{array}{c}\text { Avg. amt. } \\
\text { metabolized } \\
\text { (micrograms) }\end{array}$ & $\begin{array}{c}\text { Avg. deviation } \\
\text { from mean } \\
\text { (micrograms) }\end{array}$ \\
\hline $\begin{array}{l}\text { 17- } \beta \text { estradiol } \\
\text { Estrone }\end{array}$ & 19 & 50 & 13 \\
Estriol & 6 & 53 & 4 \\
& 6 & 21 & 11 \\
\hline
\end{tabular}

hours, the decrease in color-producing material expressed as estradiol, averaged 50 micrograms in 19 experiments using eight different rats (Table II). The amounts of estradiol metabolized by different liver samples ranged from 22 to 70 micrograms.

The results of similar experiments using estrone or estriol as substrates are also shown in Table II. In six experiments using 100 micrograms. of estrone, the average amount metabolized was $53 \mathrm{mi}-$ crograms, with a deviation from the mean of 4 micrograms. When 100 micrograms of estriol were used as a substrate, the average amount metabolized was 21 micrograms with a deviation from the mean of 11 micrograms.

2) Effect of acid hydrolysis: In an attempt to determine whether the disappearance of estrogens was due to conversion to a benzene-insoluble conjugate, one experiment was carried out using acid hydrolysis (to cleave sulfates or glycuronidates) following the usual barium hydroxide hydrolysis of the proteins. Acid hydrolysis was carried out by adding $5 \mathrm{cc}$. of concentrated hydrochloric acid to the alkaline hydrolysate and heating at $100^{\circ} \mathrm{C}$. for one hour. The results show (Table III) that this procedure did not increase the amount of estrogen recovered.

TABLE III

Recovery after incubation of 100 micrograms of 17- $\beta$ estradiol with $300 \mathrm{mg}$. rat liver-with and without acid hydrolysis

\begin{tabular}{c|c|c|c}
\hline Type of exp. & No. of exps. & \multicolumn{2}{|c}{ Recovery (per cent) } \\
\cline { 2 - 3 } & & $\begin{array}{c}\text { Without } \\
\text { acid } \\
\text { hydrolysis }\end{array}$ & $\begin{array}{c}\text { With } \\
\text { acid } \\
\text { hydrolysis }\end{array}$ \\
\hline $\begin{array}{c}\text { Incubation with fresh } \\
\text { rat liver } \\
\begin{array}{c}\text { Incubation with boiled } \\
\text { liver (control) }\end{array}\end{array}$ & 3 & 52 & 56 \\
\hline
\end{tabular}




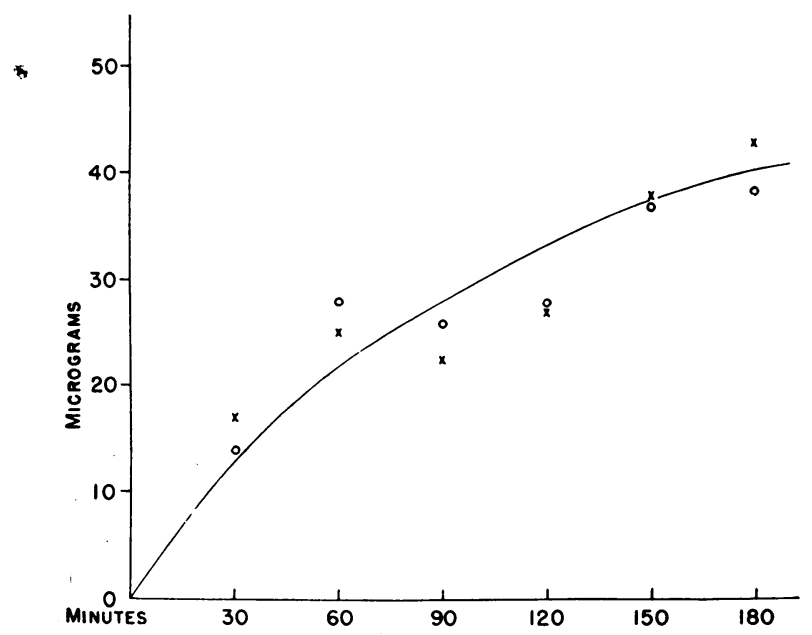

Fig. 4. Metabolism of $17-\beta$ Estradiol by Rat Liver Slices-EfFect of Time of Incubation

3) Effect of time and $p H$ : Three hundred mg. portions of the same rat liver were incubated with 100 micrograms of estradiol for $30,60,90,120$ and 180 minutes, respectively. The amounts metabolized after each time interval (Figure 4) showed a steady increase over a period of three hours.

The optimum $\mathrm{pH}$ of the reaction was found to be between $\mathrm{pH} 6$ and 7 as shown in Figure 5 .

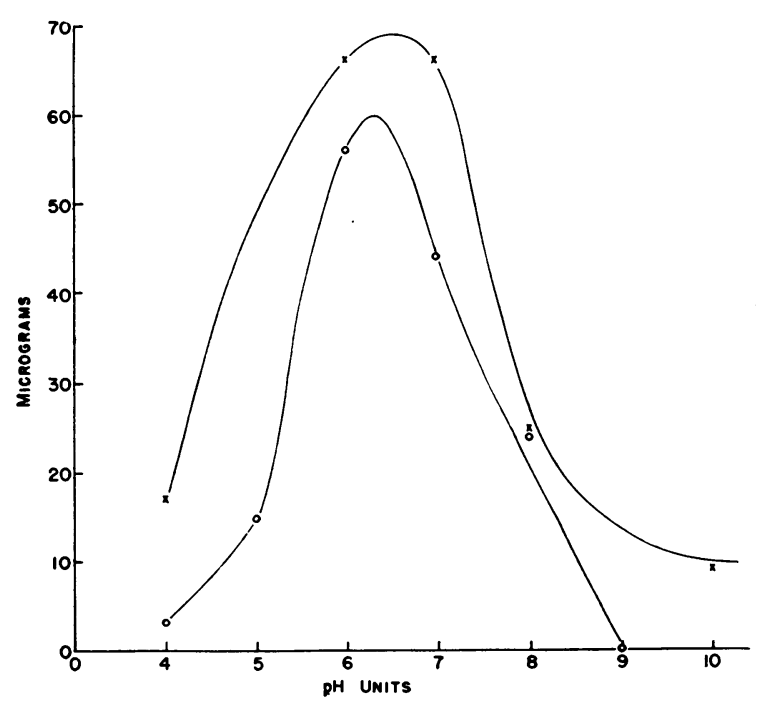

Fig. 5. Effect of pH on Metabolism of Rat Liver Slices on $17-\beta$ Estradiol

\section{DISCUSSION}

An accurate quantitative evaluation of the in vitro metabolic action of liver on estrogens is difficult by the bioassay method because each deter- mination involves a great number of injections in large series of assay animals. The limitations of the bioassay made it desirable to develop a colorimetric method capable of measuring estrogens in metabolic experiments in vitro. The method presented here satisfies this requirement. Its accuracy and simplicity make it possible to do a great number of quantitative experiments with much less expenditure of time than with bioassay. This method, obviously, does not measure the metabolic action of tissue in terms of loss of estrogenic activity, but rather measures a chemical change in the molecule of the substrate resulting in a loss of color. This change consists of an unknown alteration of the estrogen molecule which makes it unavailable for extraction or estimation by this method. Therefore, no correlation need necessarily exist between the results obtained by this chemical method, and the bioassays in biological experiments. For instance, estrone and 17- $\beta$ estradiol in equal amounts have widely different estrogenic activities in most test animals (13), while by this colorimetric method they give approximately the same color intensity. A quantitative metabolic conversion of estradiol into estrone would not be measured by our method, but would be detected by the bioassay.

There are several aspects of the method described here which deserve comment: liver and other tissues on continuous extraction with benzene yield a certain amount of color-producing material. Therefore, it is necessary to run a liver blank with the actual experimental sample to make proper allowance for the non-specific color. The duration of extraction advocated here has been found to be adequate for complete extraction of the estrogens without extraction of excessive amounts of extraneous material. The experimental data presented here demonstrate the necessity of completely hydrolyzing the tissue prior to extraction in order to achieve complete recoveries. This fact suggests that a portion of the estrogenic compounds becomes bound to the liver tissue during the incubation period in such a way that barium hydroxide hydrolysis alone, of all the procedures tested by us, could make it available for extraction. The nature of this binding between tissue and estrogens has not been studied here. In this respect, it should be mentioned that Lehninger and Scott (14) have re- 
ported a similar binding of estradiol by prostate tissue in vitro. They did not test the action of barium hydroxide hydrolysis on this binding.

Our results show that the rat liver is able to metabolize larger amounts of estradiol in vitro than previous experimental work would lead us to believe, namely, an average amount of 50 micrograms for $300 \mathrm{mg}$. of liver in three hours at $37^{\circ} \mathrm{C}$. The data indicate also that the reaction proceeds at a rather constant rate for at least three hours; this rate constitutes, therefore, a valid one for comparison of activity under different experimental conditions. The nature of the end products of the reaction between liver and estrogens in vitro is being studied and will be reported later. However, the data show that $17-\beta$ estradiol, estrone and estriol are all metabolized, as measured by the colorimetric method. This indicates that the products of the action of liver slices on estradiol probably do not consist solely of estrone and estriol. A conversion of estradiol into estrone would not account for the results reported here while a conversion into estriol could do so. The possibility and extent of such a conversion is being investigated now.

The data show also that acid hydrolysis of the barium hydrolysate did not increase the amount of color-producing material recovered in the benzene extract, indicating that the action of liver is not a conjugation. This constitutes a confirmation of the findings of Heller and Heller (3).

\section{SUMM ARY}

1) A method based on colorimetric assay is described for the study of the metabolic action of liver and other tissue on natural estrogen. The method permits measurement of 10 to 150 micrograms of $17-\beta$ estradiol, estrone and estriol with the sigma value of $7 \%$, in the presence of tissue.

2) By this method it was found that $300 \mathrm{mg}$. of rat liver slices metabolize on the average $50 \mathrm{mi}$ crograms of estradiol, 53 micrograms of estrone, and 21 micrograms of estriol in three hours at $37.5^{\circ} \mathrm{C}$. and $\mathrm{pH} 7.4$.

3) Evidence was presented that estradiol becomes bound to liver tissue in such a way that complete hydrolysis is necessary before it can be extracted.
4) The end products of the reaction of liver on 17- $\beta$ estradiol are unknown but the data suggest that they do not consist solely of estriol, estrone or conjugated estrogens.

\section{REFERENCES}

1. Zondek, B., Über das Schicksal des Fallikelhormons (Follikulin) im Organismus. Skandinav. Arch. f. Physiol., 1934, 70, 133.

2. Jailer, J. W., The metabolism of the estrogens : a review. J. Clin. Endocrinol., 1949, 9, 557.

3. Heller, C. J., and Heller, E. J., Metabolism of estrogens: Effect of pregnancy upon metabolism in vitro of estrone, estradiol and estriol. Endocrinology, 1943, 32, 64 .

4. Singher, H. O., Kensler, C. J., Taylor, H. C., Rhoads, C. P., and Unna, K., The effect of vitamin deficiency on estradiol inactivation by liver. J. Biol. Chem., 1944, 154, 79.

5. Twombly, G. H., and Taylor, H. C., Jr., Inactivation and conversion of estrogens in vitro by liver and other tissues from human cancer patients and from mice of strains susceptible to mammary carcinoma. Cancer Research, 1942, 2, 811.

6. De Meio, R. H., Rakoff, A. E., Cantarow, A., and Paschkis, K. E., Mechanism of inactivation of $\boldsymbol{\alpha}$ estradiol by rat liver "in vitro." Endocrinology, 1948, 43, 97.

7. Coppedge, R. L., Segaloff, A., Sarett, H. P., and Altschul, A. M., Cozymase as a part of the hepatic estrogen-inactivating system. J. Biol. Chem., 1948, $173,431$.

8. Coppedge, R. L., Segaloff, A., Sarett, H:, and Altschul, A., Cozymase in the hepatic inactivation of $\alpha$ estradiol. J. Clin. Endocrinol., 1948, 8, 602.

9. Haslewood, G. A. D., in Hormone Assay, edited by Emmens, C. W. Academic Press, Inc., New York, 1950, pp. 456-458.

10. Talbot, N. B., Wolfe, J. K., MacLachlan, E. A., Karush, F., and Butler, A. M., The colorimetric assay of weakly phenolic ketones, "estrone," in extracts of human urine. J. Biol. Chem., 1940, 134, 319.

11. Bender, A. E., and Wilson, A., An investigation into the chemical estimation of the estrogens in urine. Biochem. J., 1947, 41, 423.

12. Warner, R. C., The alkaline hydrolysis of egg albumin. J. Biol. Chem., 1942, 142, 741.

13. Pincus, G., in The Hormones: Physiology, Chemistry and Application, edited by Pincus, G., and Thimann, K. V. Academic Press, Inc., New York, 1948, pp. 341-343.

14. Lehninger, A. L., and Scott, W. W., The action of human prostate slices on $\alpha$-estradiol and estrone. Endocrinology, 1947, 40, 9. 